\title{
The high Resolution Paleoenvironmental Record of the Last 101,800 Years from Lago Grande di Monticchio, Italy
}

The 101,800 year record from Lago Grande di Monticchio in southern Italy $\left(40^{\circ} 56^{\prime} 40^{\prime \prime} \mathrm{N}, 15^{\circ} 36^{\prime} 30^{\prime \prime} \mathrm{E} ; 656 \mathrm{~m}\right.$ asl) illustrates the kind of detailed information about environmental changes during the last glacial that can be obtained from lacustrine sediments. This recently published multi-proxy record (Allen et al., 1999, Nature, 400, 740-743.) illustrates the potential of such lacustrine records to provide greater insight into terrestrial environmental conditions than can be obtained from either ice or marine cores. It also makes it clear that terrestrial biota were full participants in last glacial environmental changes.

The principal importance of Monticchio is that it is the first European terrestrial site to provide a continuous and high temporal resolution record of environmental change covering the last glacial with a chronology that is independent of all other records. This calendar year chronology is based upon the measurement of varves and the calculation of sedimentation rates; it is corroborated by radioisotopic dates on organic remains and tephras. This independent chronology enables not only investi- gation of the regional environmental changes and rates of change during the last glacial on a centennial to millennial scale, but also elucidation of the temporal relationships between terrestrial events and events recorded in ocean sediment cores and ice cores.

The complex paleovegetation record can be summarized in terms of the reconstructed biomes - global vegetation units characterized by a particular combination of dominant plant functional types (Prentice et al., 1992). The records for dry density, magnetic susceptibility and biogenic silica, together

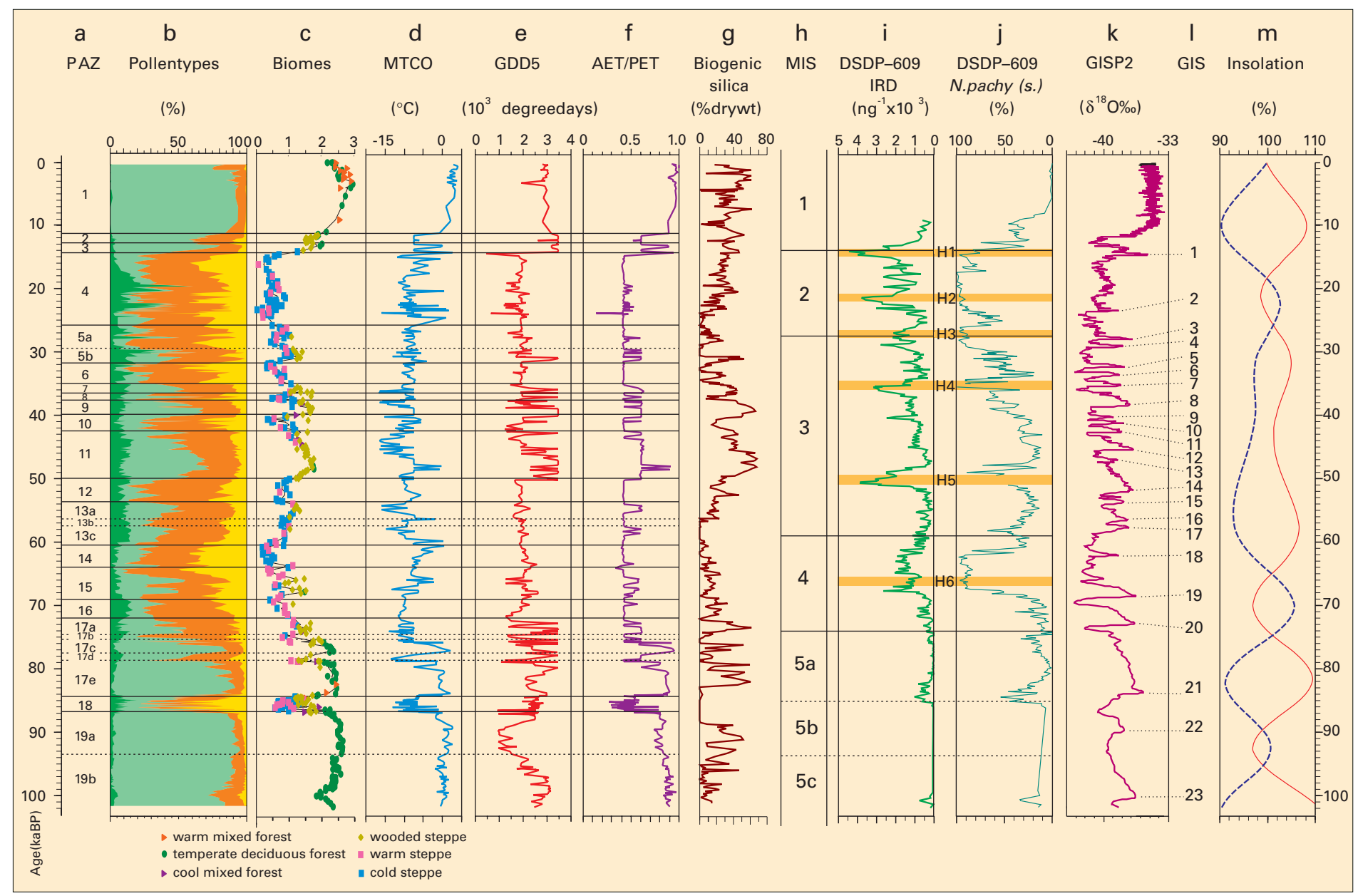

Figure 7: Monticchio pollen assemblage zones (PAZ). b. Relative abundance of pollen of Pinus subgen. Diploxylon (dark green), other woody taxa (pale green), other herbaceous taxa (orange) and Artemisia plus Chenopodiaceae (yellow). c. Reconstructed biomes plotted with respect to sample scores on the 1st axis of a detrended correspondence analysis of the terrestrial pollen data set (eigenvalue 0.39). d. Mean temperature of the coldest month (MTCO), e. annual temperature sum above $5^{\circ} \mathrm{C}$ (GDD5) and f. estimate of the ratio of actual to potential evapotranspiration (AET/PET) reconstructed from the pollen data using pollen-climate response surfaces. $g$. Biogenic silica estimated using a normative model based on X-ray fluorescence major element data. h. Marine oxygen isotope stage/sub-stage boundaries (after Martinson et al., 1987). i. Abundance of lithic grains $>150 \mu$ ( $n g-1 \times 103)$ (IRD) and j. relative abundance of Neogloboquadrina pachyderma (s.) for North Atlantic core DSDP-609 (Bond et al., 1992; Bond E Lotti, 1995). Shaded bars indicate periods of increased abundance of lithic grains related to Heinrich events (H1-H6). $k$. Greenland ice-core (GISP2) $\delta^{18} \mathrm{O}$ record (Grootes et al., 1993). l. Greenland ice-core interstadials (GIS) (Dansgaard et al., 1993). m. January (blue dashed line) and July (red solid line) insolation at $40^{\circ} \mathrm{N}$ expressed as percentages of present values (calculated at $250 \mathrm{yr}$ intervals using the program developed by Berger, 1978). Data used to plot $i, j$ and $k$ were obtained from World Data Center A (WDC-A), operated by the National Geophysical Data Center at Boulder (note reversed $x$-axis scales for $i$ and $j$ ). 
with the reconstructed biomes, show that during intervals characterised by forest/woodland biomes the catchment was more stable, there was less erosion of mineral materials and the lake was more productive. In contrast, during intervals dominated by steppe biomes the lake was less productive and the catchment was less stable.

The pollen data have been further utilized to quantitatively reconstruct paleoclimatic conditions using the pollen-climate response surfaces technique. These reconstructions indicate that moisture availability was reduced during cold and warm steppe periods compared to forested periods, with wooded steppe periods being intermediate. For most of the last glacial the reconstructed mean temperature of the coldest month was ca. $12^{\circ} \mathrm{C}$ less than the present day, with minimum reconstructed values more than $20^{\circ} \mathrm{C}$ less than present day values. During the early Weichselian forested intervals, the reconstructed coldest month temperature was close to that of the Holocene. Of particular interest in the reconstructed values of the annual temperature sum above $5^{\circ} \mathrm{C}$ is the reduction during pollen assemblage zone $19 \mathrm{~b}$ compared to the preceding subzone. This most probably reflects the decreased summer insolation at that time.

Investigations of rates of paleovegetation change show both this, and the underlying environmental changes, were often rapid: for example, increases / decreases of $>20 \%$ in the total pollen of woody taxa occur in a mean interval of $142 \pm 21 \mathrm{yr}$, whilst increases / decreases of $\geq 10^{\circ} \mathrm{C}$ in reconstructed temperature of the coldest month occur in a mean interval of $153 \pm 54$ yr. Given the average temporal resolution of the pollen data (pre-Holocene: $193 \pm 157 \mathrm{yr}$ ) these must be regarded as minimum estimates of the actual rates of change.

In the last $101 \mathrm{ka}$ of the GISP2 icecore record 22 interstadial events have been identified. When the GISP2 record, plotted on the Meese et al. (1994) timescale, is compared with the Monticchio record plotted on its independent timescale, the ice-core interstadials correlate with environmental changes seen in the Monticchio record. Prior to $65 \mathrm{ka}$, however, the Monticchio record shows greater detail than the ice-core data, pro-

continued on page 12

\section{A 800,000 Year Long Record from Owens Lake, California}

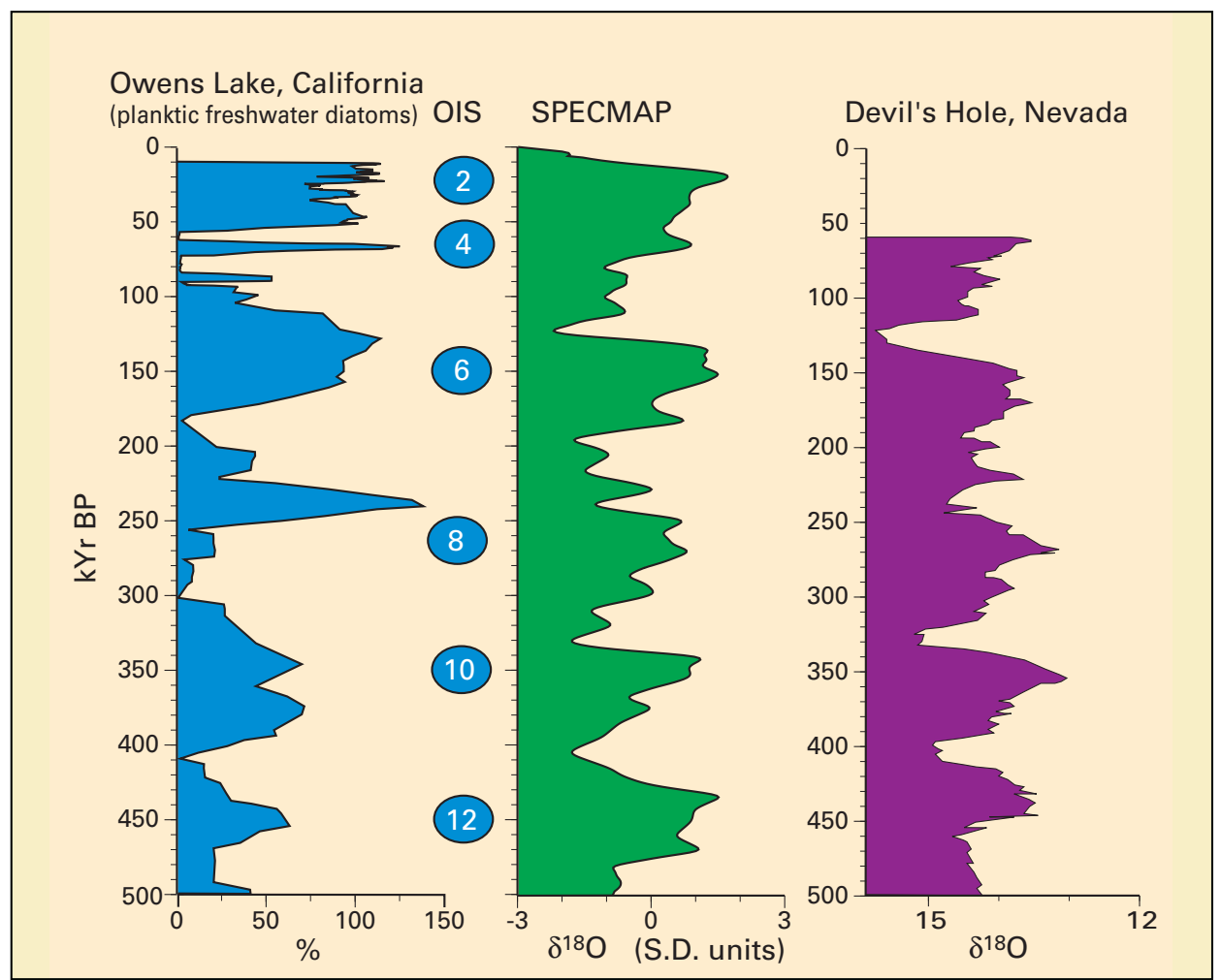

Figure 8: Owens Lake compared to SPECMAP and Devil's hole records

A 323-m ( 800 ka ) core of lake deposits beneath Owens Lake playa, Inyo County, California contains a nearly continuous paleolimnological record based on diatom assemblages. The core chronology is anchored by the Brunhes/ Matuyama boundary and the Bishop ash near the base of the record and by radiocarbon dates near the top. A tentative chronology based on mass accumulation rates appears to reliably date some volcanic ashes of known age and allows this record to be correlated with marine and terrestrial records of climate change (Smith and Bischoff, 1997).

Throughout the past $500 \mathrm{kyr}$ of its history, Owens Lake was characterized by planktic freshwater diatoms, indicating a positive hydrologic input from the Owens River and overflow of the Owens basin to lake systems downstream. Saline diatoms or sediments barren of diatoms occur in the intervals where freshwater planktic diatoms are less common or absent.

According to the Owens Lake chronology, even-numbered isotope stages of SPECMAP, representing glacial conditions, approximately match episodes where freshwater planktic diatoms dominate. The match probably indicates abundant precipitation in the Sierra Nevada in response to a southward shift of storm tracks originating in the North Pacific around the Aleutian Low which was forced to the south by the expanding Laurentide ice sheet.

The correspondence of the freshwater, planktic diatom peaks at Owens Lake to wet climates indicated by isotopes in the independently dated springdeposited carbonate at Devils Hole, Nevada (Coplen et al., 1994) is less convincing, perhaps as a result of inadequate chronological control of the Owens Lake record. Nevertheless, the strong, approximately $100 \mathrm{kyr}$ pulses indicating cool and wet climates in all these records suggests a common cause related to global climate change. When the chronology becomes independently verified or corrected, the Owens Lake lacustrine diatom record will be important for investigating the relation of lake levels and alpine glaciation in western North America to continental glaciation and global atmospheric circulation.

\section{Platt Bradbury \\ University of Bern, Switzerland \\ platt.bradbury@sgi.unibe.ch}




\section{Glacial Modulation of Rapid Climate Change During the Last 0.5 Million Years}

Two often competing priorities, the temporal length and resolution of paleoenvironmental records, may be simultaneously addressed using long cores from rapidly accumulating deep-sea sediment deposits. Site 980 of the Ocean Drilling Program's Leg 162 (Jansen et al., 1996) was drilled on the Feni Drift in the subpolar North Atlantic (Figure 2), and provides such an opportunity. The uppermost 65 meters of sediment at this site represent the last $0.5 \mathrm{myr}$, at an average accumulation rate of $13 \mathrm{~cm} / \mathrm{kyr}$, easily resolving millennial-scale features while encompassing more than four full glacial-interglacial (G-IG) climate cycles. This combination of length and resolution affords the possibility to evaluate short-term variability in the context of orbital-scale influence. Measurements of regional and global climate proxies from Site 980 reveal persistent patterns of variability, and suggest that the amplitudes of rapid oscillations are influenced by the baseline climate state, particularly the size of continental ice sheets.

Monticchio, continued from page 11

viding evidence for additional environmental fluctuations not seen in this part of the ice-core record. From this correlation with GISP2, as well as from correlations with high resolution ocean records such as that from DSDP-609, it is concluded that the Monticchio record clearly demonstrates a link between the closely coupled ocean-atmosphere system of the North Atlantic region and environmental changes in the Mediterranean region.

\section{Judy R.M. Allen}

GeoForschungszentrum Potsdam, Germany judy@gfz-potsdam.de

\section{Brian Huntley}

Environmental Research Centre, University of Durham, Durham, UK

brian.huntley@durham.ac.uk

Full references for this article can be found at www.pages.unibe.ch/ publications/newsletters/ref993.html
Stable oxygen isotope ratios $\left(\delta^{18} \mathrm{O}\right)$ in benthic and planktic foraminifera provide information about the degree of global glaciation and near-surface hydrography, respectively. The $\delta^{18} \mathrm{O}$ of the benthic species, $C$. wuellerstorfi, primarily reflects the global ice volume and the temperature of the deep ocean (Emiliani, 1955; Shackleton, 1967), while the $\delta^{18} \mathrm{O}$ of the planktic species, dextralcoiling $N$. pachyderma, bears the strong imprint of local hydrography, particularly sea-surface temperature (Keigwin and Jones, 1989; Oppo et al., 1997, 1998). Additional information about the surface ocean and the link to nearby icesheets comes from measurements of ice-rafted debris (IRD). Previous studies of the last G-IG cycle have demonstrated that sediments on Feni faithfully capture a signal of at least regional extent (Ruddiman et al., 1977; Duplessy et al., 1981; Broecker et al., 1988a,b; Bond et al., 1992; 1993; 1999; Lehmann and Keigwin, 1992; McManus et al., 1994; Labeyrie et al., 1995; Bond and Lotti, 1995).

Each of the three proxies varies in a different fashion (Figure 9), and each shares important links with the other two. The benthic $\delta^{18} \mathrm{O}$ displays the familiar sequence of glacial and interglacial Marine Isotope Stages (MIS) of the standard orbital chronostratigraphy (Emiliani, 1955; Imbrie et al., 1984; Martinson et al., 1987; Shackleton et al., 1990). By this measure, MIS 1, 5e, 9, and 11 are the most "interglacial" stages, with similarly low $\delta^{18} \mathrm{O}$ values. MIS 2, 6, and 10 have similarly high $\delta^{18} \mathrm{O}$ values, and are all surpassed by MIS 12, the most extreme glaciation of the last $0.5 \mathrm{Myr}$. The close agreement of these observations with those based on a compilation that emphasized benthic records from outside the North Atlantic (Shackleton, 1987) underscores the global significance and utility of benthic $\delta^{18} \mathrm{O}$. G-IG amplitudes of the benthic $\delta^{18} \mathrm{O}$ record at Site 980 are consistently larger $(>2.0 \%$ ) than those outside the region. These larger amplitudes, combined with the consistent relationships among respective glacial and interglacial extremes, indicate that not only did the deep North Atlantic experience a particularly large temperature change during the last G-IG cycle (Duplessy et al., 1980), but that it must have undergone equivalently large temperature changes relative to the global deep ocean during previous cycles.

IRD varies throughout the record, with a markedly episodic character that contrasts with the more smoothly varying benthic $\delta^{18} \mathrm{O}$. The youngest IRD episodes represent the catastrophic discharges that punctuated the last ice age (Heinrich, 1988; Broecker et al., 1992; Bond et al., 1992; cf review by Andrews, 1998), and comparable features occur throughout the record. Each glacial interval contains several IRD events, the last of which (McManus et al., 1994; Venz et al., 1999) is associated with the rapid deglaciation, or termination (Broecker, 1984) that marks the transition to the subsequent interglacial stage. IRD peaks are only associated with benthic $\delta^{18} \mathrm{O}$ values above approximately 3.5\% , suggesting a threshold for iceberg discharge.

The $\delta^{18} \mathrm{O}$ of dextral-coiling N. pachyderma displays large-amplitude variations, with several G-IG cycles of 3.0\% . Although such a range of values is remarkable, it is less than the equivalent range suggested by the broad temperature tolerance of this species (Be and Tolderlund, 1971; Kipp, 1976; Pflaumann et al., 1996), and by measurements of modern specimens (Figure 9). Only MIS 5e slightly surpasses MIS 1 as an interglacial extreme, and is approached by both MIS 9 and MIS 11. MIS11 is by far the longest interglacial, including a warm, IRD free interval of 30-40kyr. MIS 12 is the coldest glacial stage, as well as the most glaciated, followed by MIS 2, 6, and 10. Rapid oscillations of approximately $1.0 \%$ occur within the glacial stage of each large cycle, whereas peak interglacial variability is limited to less than $0.3 \%$. As with the IRD discharges, benthic $\delta^{18} \mathrm{O}$ values of approximately $3.5 \%$ mark the transition between more and less variable modes of millennial-scale variability. After correction for the ice volume effect on $\delta^{18} \mathrm{O}$ (Labeyrie et al., 1987; Fairbanks, 1989; Schrag, 1996), the planktic isotopic variations represent sea surface temperature (SST) changes of $8-9^{\circ} \mathrm{C}$ for each G-IG cycle. On shorter timescales, the SST 